Journal of History Culture and Art Research (ISSN: 2147-0626)

Tarih Kültür ve Sanat Araştırmaları Dergisi

Vol. 9, No. 3, September 2020

\title{
DOI: 10.7596/taksad.v9i3.2647
}

Citation: Kablova, T., \& Teteria, V. (2020). Popular Song Creativity in the Socio-cultural
Context. Journal of History Culture and Art Research, 9(3), 147-154.
doi:http://dx.doi.org/10.7596/taksad.v9i3.2647

\section{Popular Song Creativity in the Socio-cultural Context}

\author{
Tetiana Kablova ${ }^{1}$, Victor Teteria ${ }^{2}$
}

\begin{abstract}
This article investigates the influence of modern social processes on musical culture, in particular, on vocal pop songs in the Ukrainian context. The culturological vector in the formation of popular vocal and song creativity as a mass culture in the context of the social and historical stage of human existence is emphasized, the concept of pop vocal music is considered. One of the most serious stages in the development of pop music culture in the context of social processes, the authors consider the problem of simplifying the concept of pop vocal popular art, its humiliation in comparison with academic vocal culture. At the same time, in the context of modern social and historical development, the emphasis is on the formation of a special kind of mass art-popular art, which becomes a mirror of socio-historical events that are important for a particular time. At the same time, in the context of modern social and historical development, the emphasis is on the formation of a special kind of mass art-popular art, which becomes a mirror of socio-historical events that are important for a particular time. The authors provide their statements about the presence in vocal and pop music of important psychological phenomena of thought, feeling, sensation, perception, judgment, which are essentially a symbolic composition of personal consciousness. It is determined that such symbolism is most fully and deeply revealed in the context of the genre content of pop vocal performance, which today is defined as a new academicism, i.e. deep and concretized professionalization that provides its own socio-communicative and expressive-artistic canons, forms the basis for understanding and interpreting events of modernity and socio-cognitive function.
\end{abstract}

Keywords: Mass art, pop music, singing, musical culture, song creativity.

\footnotetext{
${ }^{1}$ Ph.D. in Arts, Associate Professor, Head of the Chair of Instrumental and Performing Arts, Institute of Arts of Borys Grinchenko Kyiv University, Kyiv. http://orcid.org/0000-0002-0954-8422 E-mail: t.kablova@kubg.edu.ua

2 Professor of academic and variety singing, Institute of Arts of Borys Grinchenko Kyiv University. http://orcid.org/0000-0002-6172-9255 E-mail: v.teteria@kubg.edu.ua
} 


\section{Introduction}

Among the contextual explication of musical art, vocal and pop performance deserve special attention. This is justified by the fact that for a long time pop music and performance were not part of the constant study of scientists and did not cause the need for deep immersion in their specifics. Today we can observe a significant spread of pop performing arts at all levels of socio-cultural space, as well as art education: in primary art institutions, out-of-school and high education institutions of all levels of accreditation. Such a demand for awareness in the field of pop performance requires careful study of all its components not only at the level of methodology, but also at socio-cultural level.

The growing role in the life of pop performance in the organization of cultural space makes the urgent need to explain its nature. Along with this, the importance of the question of national identity is growing, at the same time, the European professionalism of the Ukrainian vocal stage and chronotopic principles of genre stratification of Ukrainian vocal pop performance expand. Among the main trends in the stylistic development of vocal and pop performance, academia stands out, but with special features, i.e. significantly updated and rebuilt relatively previous stable classical forms. Besides, in the field of pop music, there is already its own "classics" and other values, similar to artistic aesthetic criteria of traditional "serious" musical creativity.

In short, there is a need to explore pop music, to consider the main factors and conditions of existence of vocal and pop performance of Ukraine in the late 20th - early 21st century, to consider the concept of pop as a basis for today's development of art.

\section{Methods}

The methodological base is formed by the sum of methodical approaches, among which the main ones are culturological (allows to reveal the genre nature of vocal and pop performance and semantics genre forms in the field of pop art), semiological (leads to study of specific features of verbal and musical language that lies based on pop singing), textual (due to interpretive specifics of music variety), and comparative art history (provides a broad, but at the same time analytically in-depth, comparison of different artistic types and forms). Dialogic discursive becomes a generalizing approach, develops throughout the study, and defines its categorical guidelines. The problem posed in the study requires integrated involvement of methodological approaches of such related branches as philosophical aesthetics, social psychology, music psychology, cognitivistics, musicology, and vocal pedagogy.

\section{Discussion}

Pop is traditionally defined as an art that encompasses musical (song, instrumental), choreographic (dance miniature), theatrical (interlude, sketch, feuilleton), and circus (juggling, balance, acrobatics, training) genres. Based on the stage practice, the main components were differentiated, which, however, retain significant relationships (up to the creation of a synthetic action - a show). Pop music determination as a special kind of art that combines almost all spatio-temporal arts, which also convinces of its versatility. Although, it should be noted that the foundations of mass vocal art were laid in the process of changing the paradigms of classicism and romanticism. Romanticism quickly succeeded in conquering the "people" who never perceived the old classical art as their own. The enemy with whom romanticism had to contend was precisely the chosen minority, 
petrified in the archaic "old-regime" forms of poetry. Ever since book printing was invented, romantic works were the first to have a large circulation (Stokes, 1994).

It should be noted that the patterns and features of the development of various forms of mass music culture have built aesthetic features of pop vocal in particular adherence to certain standards (universal values, ideal, universality, focus on tradition, etc.). These elements and structures in vocal and pop music play the role of aesthetic, formative, and linguistically expressive stereotypes. It is clear that the basis for vocal and pop music remains an illusory basis, simply that within the mass music culture remains an undemanding style and easy distribution of officials who were found by the event.

Researchers point out that the separation of popular vocal music is the most influential in terms of artistic traditions and new relationships. That is also understood as public vocal music, which is unconditional, made by the average broad listener of the human mass, which contains the traditions of national independence from the style and time of its creation (Bobul, 2019).

Today, the concept of pop is more related to the localization of performances by musicians, singers, and others. Where there is a presentation to the public of mostly small forms of musical (musical-dramatic) works (Dolfsma, 2000). Note that this concept also includes a centralized system of organization of concert and entertainment performances, as well as applies to the professional artistic community as a whole. The main function of pop art is to create a space for psychological relief of the mass audience and listener, response to problematic moments in real life and real feelings that are inherent in all individuals. Interesting and accurate is the statement of the American art critic G. Sands, who interprets pop art as the deepest and most accurate reflection of the time in which it is popular and in demand, compared with academic art, which aims at a more timeless dimension of existence.

The rapid spread of vocal and pop art was due primarily to the rapid development of the media. Total accessibility due to the latest technological advances have led to the constant dominance of such art in human life. Spectacular and entertaining, promoting among the widest audiences the ease of perception for the spread of Ukrainian pop music have become substitutes for academic and utilitarian types of culture, which differed depending on the socio-economic situation of its consumers. In addition, the desire for entertainment was quite natural, given the two world wars experienced by mankind, the confrontation of different totalitarian regimes, and so on.

Another factor in the spread and flourishing of pop culture was that its creators felt in time the time of appearance in the public of sufficient funds to pay for a unified cultural product. The means of reproduction and distribution of music became more accessible and at the same time more perfect, and the desire of the public to perceive quality shows became stronger. For the poor, mass culture became a "window into the world of art", which was not provided by official culture, on the contrary, it distanced the common man from the beautiful. Instead, mass culture in its vocal and pop manifestation, although based on the promotion of the phenomena of primitive aesthetics, also contributed to the socialization of man, allowing him to effectively master the necessary social skills and create a socially-oriented image around him.

The culturological vector of vocal and pop performance extends in the anthropological direction in the context of the historical and cultural meaning of the existence of a particular society, which in turn is the carrier as a collective unconscious in the process of perception of a work of art. That is one of the tasks in the field of pop and vocal performance is the coverage of socio-cultural semantics of 
the existing generation. In other words, the formation of interaction between the genre nature of this industry and the emotional and sensory factors of human culture. Thus there is an objectification of the existing emotional factors of human development in the appropriate art form, which becomes part of the "live world" to the extent that reflects his psychological system and affects him. The point is that the human personality at all times of its existence needs a certain response from the world around them. In the social context, we can see that in the so-called "light" music are globalized, presented, and perceived the most difficult issues of human existence in an understandable and sufficiently popular art form. Vocal art, namely popular pop song is the closest to man (Kablova \& Teterya, 2015). Therefore, it is important to reveal those aspects, genres, and stylistic features of pop song that allow it to gradually transform from "light" music to serious, in demand by the general public consciousness, art. This art is able to offer and solve pressing issues of both social and individual human life. That is to express feelings of personality and demonstrate them in unity and deep affinity with the general sociocultural space, which provides the effect of "mass", in its positive meaning, which distinguishes pop song. It is necessary to explain the fact that today in Ukraine the same as all over the world so-called mass entertainment, i.e. popular mass music persistently academized, acquires (actually, already acquired) signs of secondary artistic professionalism, the requirements of which are organizational technological sphere and means of communication, as well as artistic preparedness and personal and psychological qualities, even superior requirements for musicians of "traditional academy orientation" (Jeffries, 2003). Virtually every national song culture in the 20th century developed, formed, and variously updated its original pop song genre style. Studying the evolution of the pop song, I. Bobula rightly finds in it, on the one hand, a special kind of "sublime", but secondary (according to G. Besseler), a genre in which there is a system of communication that has developed in modern music, including public concert performance.

The main unifying factor, an effective artistic and organizational, the center becomes the figure of the performer-singer, and of the artistic-communicative functions to the forefront is the global function of "portraying social individuality" by means of vocal voice (Habermas, 1985). Hence the definition of the main communicative strategy of the song genre as one that is based on the personality of singers, especially - on their vocal and vocal qualities, intonation capabilities of pop solo singing, which is thus a special performance-psychological phenomenon, causing a special attitude to those who directly embody this phenomenon.

Thus, the song in its everyday form does not require special knowledge and skills and more often functions as an emotional sphere of a person's embodiment of their experiences and joys by means available to others. Accessibility is of paramount importance here, because it is through the unity of certain social groups through the available means of art that the mass nature of one or another kind of art in the cultural space of existence is revealed. In turn, this allows us to talk about the peculiarities of the response of the human environment to its emotional coding by means of the song of their experiences, as well as the mechanisms of purposeful formation of the availability of emotional code. The means of musical expression promote the empathy of the performer of the inner state of the lyrical hero, and accordingly, the mass audience.

Vocal and pop music is a powerful mirror of the socio-historical continuum of its functioning. This is due to the fact that one of the conditions is the factor of its replication, which is possible only under conditions of saturation with peculiar intonation, verbal, and stylistic formulas of time. The point 
is that the aesthetic parameters of the interaction of mass pop music with the recipient, the consumer of vocal and pop product are based on culturological and sociological factors, which are aimed at the external design of the number, the style of behavior of the performer.

If we are considering the dialogue of music with the audience, we can claim that the created music is the poetry of the human soul, a means of communication between the listener and a carrier of inexhaustible information and cultural content (Samoylenko, 2002). Musical meaning, the nature of musical semantics are universal dominants, the study of which makes it possible to achieve deep analytical dimensions of art. That is, based on this, we can talk about the existence in vocal and pop music of the psychological phenomenon of thought, feeling, feeling-perception, judgment-concepts, which are significant for a person, that is, express the symbolic arrangement of personal consciousness. The genre-style content of pop vocal performance, endowed with the qualities of a new academicism, i.e. in-depth and specified professionalization, which provides its own socio-communicative and expressive-artistic canons, is most fully and deeply revealed in the context of theory of understanding and interpretation, i.e. as socio-cognitive. Note also that the category of socio-cultural communication we understand in connection with artistic activity and position as aesthetically productive and constructive in action-activity and immanent-psychological plans interpersonal communication.

Thus, accessible to all ages and segments of the population, vocal and pop music should have the widest audience, because it is aimed at meeting the instantaneous time demands of people and responds to any new events in society. Contemporary pop music has specific artistic features and means of expression, is characterized by a typical manner of contact with the audience, acting skills, and the ability to instant reincarnation.

Now pop culture has come to the point that theatrical pop forms are becoming the basis as simpler means of combining vocal numbers, including rock operas and musicals, and the use of stylized folk samples forms the pinnacle of the genre system of music and pop art, in particular, crowns solo concerts and singing practice. Although it is the proximity to folk samples that can overcome the barrier of perception of any pop-vocal form.

The formation of Ukrainian vocal and pop music culture can be marked by ease of perception due to stereotypical intonation formulas, mainly of folk origin. Regardless of socio-political realities and processes, the folk song is a universal form of national and cultural identity. Differentiation of folk songs by genres and types depends on the degree of traditionalization of socio-cultural experience of the ethnos. The peculiar evolution of folklore in the context of the interaction of collective-individual (folk) and individual-collective (professional-literary) became the basis for the spread of modern pop and vocal art.

This led to the evolution of form-stylistic, melodic-linguistic, textural-genre components of modern song pop. The essence of stylistic democracy of mass music, in particular pop music, forces to care about the development of new norms not only aesthetics, stylistics, and taste, but also the potential of mass use of those elements of pop which under conditions of competent application impress public. The rhythmic beginning of pop music reflects the stylistic features and figurative characteristics of a musical work, it is one of the most important means of expression, which stimulates the creative imagination of the musician-performer. The strengthening of folklore in Ukrainian pop music has led to the following trends in its development: the widespread use of folk song aesthetics while borrowing the latest musical techniques; professional "folklorization" and stylization of pop 
works - representatives of rock and pop music; the growing interest of academic composers in music, which significantly influenced the growth of its artistic level and enrichment of the singing repertoire. Under such conditions, the stylistic democracy and universality inherent in modern mass music culture do not threaten the loss of national identity, but are an impetus for its further development.

From the point of view of the chosen topic, it is interesting to implement the comparative analysis of mass music with academic music and folklore. Characterizing today's vocal and pop music as a spiritual and cultural phenomenon, we should focus on it as an ambivalent formation, which organically combines elements of professional music and folklore, which allows to realize the functions of socio-cultural integration and socialization of the individual in the modern world. On the other hand, it is the mass society that needs art that is able to respond quickly to the continuous growth and variability of its demands.

Today, the processes of globalization, which are manifested in the art of music, lead to the need to find creative interaction between all components of world music: the requirements for professionalization of pop song, standardization of its typical components, and individual search for new forms in the horizons of national vocal performance. Spacious vocal and pop music is interpreted from the standpoint of the purpose of mass and compliance with the criteria of today's popularity of a wide audience. But during its formation, especially in Ukraine, it is possible to identify the tendency to improve professional quality in the field of pop and vocal performance. This forms such a defining feature of the modern pop space, namely the combination of popular and elitist value approaches through the prism of national traditions.

So today in most genres of Ukrainian vocal and pop music - in the lyrics, in the stylistic sphere (often also in the visual series or scenography), etc. - there is a strong emotional, psychological, and aesthetic potential of the traditions of national vocal lyrics.

In general, the modern vocal and pop performance of Ukraine presents all traditional areas of existence, namely club art, performing arts (as defined by the Ukrainian Cultural Foundation), jazz, and art of the rock.

The most accurate today is the performative art in the field of pop and vocal performance, because this type allows you to demonstrate the typical modern synthesis of arts from the standpoint of combining different types of artistic features, the condition of which is the interdependence of different generic aesthetic categories, epic, dramatic and lyrical beginnings, because it is in the performing arts, they found new artistic qualities and opportunities, ways of interaction. Today this includes not only solo concerts of modern pop stars, which are also characterized as certain stage acts, but also musicals, operettas, rock operas, and more.

As for club pop culture, it is a separate sphere of existence of vocal pop performance, which provides for the use of different types and genres of song music in closed, different-scale venues. According to the orientation of the club, the whole spectrum of performance can be used: from jazz to rhythmic-dance song samples. This area is the clearest example of the manifestation of subcultures in the pop industry.

One of the main components of the modern pop space is also rock culture. It should be emphasized that this area, on a par with singing as such, was developed in the Ukrainian art of the late twentieth century. Ukrainian rock exists in the form of entertaining music, which does not carry an in- 
depth semantic load, and intellectual, where there are conceptually significant ideas of society. Today, rock is not only a form of culture or a musical direction, but it is also ideals that are the result of public

Thus, the development of pop and song art is extremely diverse: individual art styles are born today in a situation of total synthesis, reflecting the pluralistic view of artists on the world, is a reproduction in music of various worldview dialogues, different points of view on life. The worldview of modern man presupposes a breadth of beliefs. In specific individual styles, this often materializes through a combination within one work of completely incompatible at first glance intonation-semantic principles.

Of course, all these researches are aimed primarily at meeting the requirements of time, listeners, and fashion. Given this, the music business is primarily a system of profit, which determines the richness of genres and styles used in it, while folk music (as a historical phenomenon, as well as a fundamentally non-business sphere of music culture, i.e. the offer of authentic music), according to T. Avery (2017), is an alternative opportunity for popular music produced by the music business.

\section{Conclusion}

Summing up, we can say that today pop and vocal music is developing in all available traditional and new synthesized genres and claims a unique role in shaping the psychological portrait of modern man. It develops as a genre that allows the creation of its own axiology and mythology, which correlate with modernity as a range of events where borrowing is treated as a sphere of unity, and the solution of complex life problems by means of existing experience of society, its perception and evaluation, and in artistic meanings.

Modern pop spectacle is complex in its structure. It covers not only the artistic work of the performer but also no less intense and creative efforts of the production team. Therefore, the organizational and staging aspect of modern music is no less important than its own performance as such. The complexity of modern pop style stylistics implies its ability to cover all spheres of life and, as a result, to meet any tastes and needs. Vocal voice - singing - a conditional stage role, corresponding to the content of the song reveal the inner psychological boundary of the stage space as artistic and with special artistic intentions created. Pop singing is the central link in a rather long chain of artistic communication, which begins within the vocal culture as a socio-historical and national-stylistic phenomenon, and leads to individual authorial creativity and individual compositions, and thus to specific textual conditions for specific tasks of pop art. The recognition of the main dominants of creative work in the form of musical and scenic forms of the folding genre form, based on a wide, generic aesthetic synthesis, is reserved. It has been stated that a musical theater is open - the genre sphere is folded up and vibrated, it has gone through historical development and has not yet reached the remaining European level, but it has entered into a modality with such types of music, opera; "bagato spilnogo" in the semantic sphere. Preservation of mass nature, purpose to a wide audience and meeting the criteria of popularity a fundamental genre feature of pop vocal creativity, on the one hand; on the other hand, the whole modern stage of its development testifies to the persistent improving professional quality, including in the forms and means of educational and creative system, and this determines the antinomy of vocal pop art as its institutional and semantic paradagmatic feature. 
Picture of the world, created in pop and song creativity, fortified with professional principles of pop vocals, meets the task value regulation of life experience of culture, then - a separate personality. It is designed to be the only fabric for the social awareness of qualitative qualifications of the inner psychological world of man, that is, to promote the coordination of one with the other, the harmonization of cognitive process in cognition and self-knowledge of the laws of the common human being, improving the ability to feel yourself and others, to understand what evidence of these feelings (compassion). Popular vocal creativity claims a special place in psychological "world of life" of the average person, due to the ability to activate consciousness and push personal "horizons of expectation".

It is developing as a genre industry that allows the creation of its own axiology and mythology, addressed to modern reality, also involves borrowing-repetition, although within certain limits, uses high ethical motives, dramatic plot conflicts, complex life problems, but solves them by means of "commonplaces" and appeals to the already existing experience of perception and evaluation, both in general and artistic meanings.

\section{References}

Avery, T. (2017). Globalization in the music industry. Discover. Share. Learn. https://www.slideshare.net/Teyland/globalization-in-the-music-industry

Bobul, I. (2019). Genre forms and stylistic connotations of vocal and pop performance in music culture Ukraine of the late XX - early XXI century. (Ph.D. dissertation). Kyiv, National Academy of Managerial staff of Culture and Arts.

Dolfsma, W. (2000). How Will the Music Industry Weather the Globalization Storm? First Monday, 5(5). https://journals.uic.edu/ojs/index.php/fm/article/view/745

Habermas, J. (1985). The Theory of Communicative Action (trans. from German by Thomas McCarthy). London: Beacon Press, Vol. 1: Reason and the Rationalization of Society.

Jeffries, S. (2003). Encyclopedia of world pop music: 1980-2001. London: Greenwood Press.

Kablova, T., \& Teterya, V. (2016). Folk song as an intentional component in the work of M. Lysenko. Relevant problems of history, theory and practice of art culture volume 37 http://elibrary.kubg.edu.ua/17241/1/T_Kablova_V.Teterya_AP_n37_2016\%20(1).PDF

Samoylenko, O. (2002). The phenomenon of the artifact in the context of the psychological arts. Musical arts and culture: Science Bulletin of Odessa state Conservatory. A.V. Nezhdanova. Volum 3 Odessa: Astroprint.

Stokes, M. (1994). Ethnicity, Identity, and Music: the Musical Construction of Place. Oxford: Berg Publishers. 